\title{
Erratum to: Voting power and proportional representation of voters
}

\author{
Artyom Jelnov • Yair Tauman
}

Published online: 17 June 2015

(C) Springer-Verlag Berlin Heidelberg 2015

\section{Erratum to: Int J Game Theory (2014) 43(4):747-766 DOI 10.1007/s00182-013-0400-z}

Please publish an erratum regarding the following four errors:

1. Page 754, line 14, should be $\sum_{i \in P_{1}^{\Re}} x_{i}$ instead of $\sum_{i \in P_{1}^{\Re}} x_{1}$.

2. Page 760 , lines 17 and 20 , should be $A_{n} \backslash E_{n}$, not $A_{n}^{\prime} E_{n}$.

3. Page 760, line 18, should be $\max _{1 \leq i \leq n} x_{i}$ instead of $\max _{1 \leq i \leq 4} x_{i}$.

4. Page 760, line 20, should be Exp, not EXP.

The online version of the original article can be found under doi:10.1007/s00182-013-0400-z.

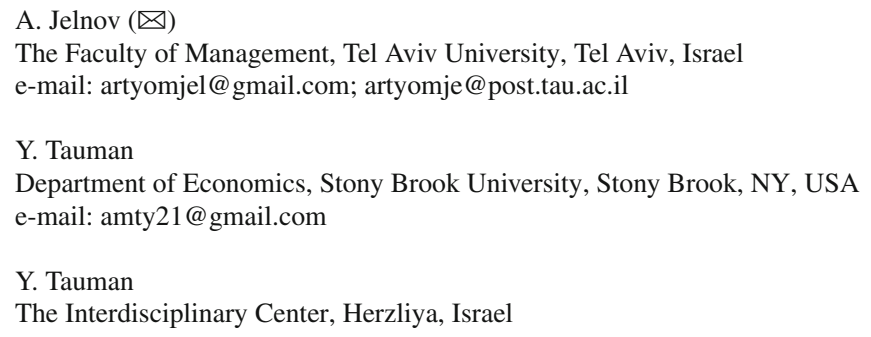

